infections enhance disease are open to speculation. Some effects of dual infection may simply be due to production of interferon, but the true mechanisms of interaction remain largely unknown. Physical effects at the epithelial or mucosal site of entry may be important, and antigens may compete for the attention of the immune system after entry into the host. Most pathogens have probably evolved elaborate molecular methods of interfering with the immune response, and the well adapted host has probably got molecular counterstratagems which might be relatively specific to a single infecting agent. The complexities of the processing and presentation of antigens are only recently becoming clear, while the checks and balances present within even the currently known network of immune cytokines are so complex that effects in intact lymphoid organs are almost impossible to predict.

The sheer number of clinical and subclinical infections that occur in the first years of life makes simultaneous infections common. In the laboratory we strive to study infections by single agents, but this event is probably rare even in the best controlled experiments. In real life infections do not occur in isolation and need to be viewed in the context of the previous and concurrent experience of the immune system. The potential complexity of dual infections is daunting, but it needs to be taken into account if we are to unravel the immense variations in disease.

Wellcome Trust Senior Research Fellow in

P J M OPENSHAW

Clinical Sciences,

Respiratory Unit,

St Mary's Hospital Medical School,

London W2 IPG

1 Moore PS, Hierholzer J, DeWitt W, Gouan K, Dioré D, Lippeveld T, et al. Respiratory viruses and mycoplasma as cofactors for epidemic group A meningococcal meningitis. JAMA $1990 ; 264: 1271-5$.

2 Cartwright KAV, Jones DM, Smith AJ, Stewart JM, Kaczmarski EB, Palmer SR. Influenza A and meningococcal disease. Lancet 1991;338:554-7.

3 Harrison LH, Armstrong CW, Jenkins SR, Harmon MW, Ajello G, Miller GB, et al. A cluster of meningococcal disease on a school bus following epidemic influenza. Arch Intern Med 1991;151:1005-9.

4 Nichol KP, Cherry JD. Bacterial-viral interrelations in respiratory infections of children. $N$ Englf Med 1967;277:667-72.

5 Loosli CG. Influenza and the interaction of viruses and bacteria in the respiratory tract. Medicine 1973;52:369-84.

6 Eichenwald HF, Kotesvalov O, Fasso LA. The "cloud baby": an example of bacterial-viral interaction. Am F Dis Child 1960;100:161-73.

7 Krober MS, Stracener CE, Bass JW. Decreased measles antibody response after measles-mumpsrubella vaccine in infants with colds. FAMA 1991;265:2095-112.

8 Peter G. Measles immunisation: recommendations, challenges, and more information. FAMA 1991;265:2111-2.

9 Hutchins SS, Escolan J, Markowitz LE, Hawkins C, Kimbler A, Morgan RA, et al. Measles outbreak among unvaccinated preschool-aged children: opportunities missed by health care providers to administer measles vaccine. Pediatrics 1989;83:369-74

10 Knight V, Fleet WF, Lang DJ. Inhibition of measles rash by chickenpox. FAMA 1964;188:690.

11 Contag $\mathrm{CH}$, Harty JT, Plagemann PGW. Dual virus etiology of age-dependent poliomyelitis of mice. A potential model for human motor neuron diseases. Microb Pathog 1989;6:391-401.

\title{
The rise and fall of chorionic villus sampling
}

\section{Midtrimester amniocentesis is usually preferable}

For prenatal diagnosis, which is better: chorionic villus sampling in the first trimester or amniocentesis in the second? Two years ago a large Canadian study comparing the two procedures suggested that fetal losses were slightly higher in those women randomised to chorionic villus sampling. ${ }^{.}$Now the even larger Medical Research Council European trial has confirmed this: of women allocated to amniocentesis $91 \%$ had a live baby who survived, significantly more than the $86 \%$ who were allocated to chorionic villus sampling. ${ }^{2}$

Much of this difference was accounted for by significantly higher fetal loss before 28 weeks' gestation and more pregnancies terminated for chromosomal anomalies in the women allocated to chorionic villus sampling. (Some of the pregnancies in the chorionic villus sampling group were terminated for chromosomal abnormalities that may have been lethal by the time of the amniocentesis; if so the quoted difference in miscarriage rates underestimates the true difference in miscarriages related to the procedure.) Experienced operators can achieve much lower rates of fetal loss after both transabdominal and transcervical chorionic villus sampling than were reported in these studies, ${ }^{3}$ and some improvement in differential loss rates was noted during the Medical Research Council trial itself. On the basis of these two trials, however, we must conclude that chorionic villus sampling is riskier than amniocentesis for the fetus.

Of possibly greater concern to parents is a putative link between placental biopsy and limb abnormalities. One baby in the chorionic villus sampling group in the Medical Research Council trial was delivered with an oromandibularlimb hypogenesis syndrome-one of four cases already reported from Oxford. ${ }^{4}$ This prompted many subsequent reports of limb defects in association with chorionic villus sampling, including three further cases of combined limb and facial abnormalities, from Italy,${ }^{5}$ China,${ }^{6}$ and Germany. ${ }^{7}$ As the expected incidence of this condition is less than one in 100000 it seems quite likely that we are dealing with a real effect rather than random clustering, but this cannot be proved in the absence of complete ascertainment of all congenital anomalies following chorionic villus sampling (the numerator) and a reliable estimate of all procedures carried out (the denominator).

In addition to the risk of the syndrome of limb and facial abnormalities, the risk of transverse limb defects in general was found to be increased in a case-control study from Italy, where the popularity of chorionic villus sampling makes this method of analysis possible. ${ }^{5}$ Three reports totalling 25000 procedures were published in response to these data, and 13 cases of transverse limb defects were found. ${ }^{7.9}$ Based on the Poisson distribution for rare events, the probabilities of obtaining this (or a more extreme) result are 0.008 and 0.07 for baseline incidences of $1.8^{10}$ and $3.3^{5}$ in 10000 respectively. Publication bias is unlikely as there were no significant associations within individual series and authors therefore published their results as reassuring evidence. The apparent causal association between chorionic villus sampling and limb reduction defects is greatest before nine completed weeks of pregnancy, suggesting that the embryo should be left alone during the phenocritical stage of development. ${ }^{11}$

Chorionic villus sampling retains its great advantage over midtrimester amniocentesis by providing early results, although this potential benefit is not always realised. This is because the test throws up ambiguous mosaic results more often than amniocentesis, and as three quarters of these are confined to the placenta subsequent confirmatory tests may be required in later pregnancy. ${ }^{12}$ Both chorionic villus sampling and amniocentesis may miss small chromosomal deletions, and both produce very few false negative results for trisomy. With chorionic villus sampling, however, this is achieved only 
if "direct" karyotype analysis of rapidly dividing trophoblast nuclei is combined with conventional culture of slowly dividing cells from the mesenchymal cores of the chorionic villi. ${ }^{12}$

Even before publication of the Medical Research Council trial, members of the prenatal study group (sponsored by the Royal College of Obstetricians and Gynaecologists and the Department of Health) had concluded that chorionic villus sampling has the greatest relative value for women with a higher risk of having genetically abnormal babies, such as those at high risk of a single gene defect or unbalanced translocation of chromosomes. There are several reasons for this. Firstly, the risk of miscarriage (and perhaps other adverse outcomes) is higher with chorionic villus sampling than with amniocentesis: these fixed risks remain the same while the benefits of early diagnosis become proportionately more important as genetic risk rises - a point that has been proved formally using decision theory. ${ }^{13}$ Secondly, most invasive prenatal diagnostic procedures are performed in women who are at low risk of trisomy, and the cost of chorionic villus sampling for cytogenetic indications is double that for amniocentesis because both direct preparations and culture are needed. ${ }^{1+}$ And, lastly, ambiguous cytogenetic results requiring subsequent elucidation are four times more common with chorionic villi than they are with cultured amniotic fluid. Chorionic villi, on the other hand, provide large amounts of metabolically active cytoplasm and DNA for enzyme and gene probe diagnosis in single gene defects with high recurrent risks.

"Real time" ultrasonography allows amniocentesis to be performed at 12 weeks' gestation or less. Could this provide the best of both worlds? Amniocentesis may cause pulmonary hypoplasia, ${ }^{15}$ however, and animal experiments suggest that this risk is inversely proportional to gestational age ${ }^{16}$ Several randomised trials are looking for this and other adverse effects of early amniocentesis. These trials are likely to detect only large increases in rare side effects ${ }^{17}$; hence the possibility of iatrogenic harm below the threshold of statistical detection must be included in counselling, especially when couples at low risk request prenatal diagnosis. This is a strong argument for using other markers (such as biochemical variables and ultrasonic appearances) rather than age alone to determine the risk of aneuploidy.

Those of us who wish to avoid central licensing of all surgical procedures ${ }^{18}$ will be able to resist it more persuasively if we subject new techniques to voluntary scrutiny by randomised controlled trials. These two large studies that have compared different prenatal diagnostic procedures are good examples of the voluntary assessment of invasive procedures.

Professor of Obstetrics and Gynaecology, St James's University Hospital,

Leeds LS9 7TF

1 Canadian Collaborative CVS-Amniocentesis Clinical Trial Group. Multicentre randomised clinical trial of chorionic villus sampling and amniocentesis. Lancet 1989;i:1-6.

2 MRC Working Party on the Evaluation of Chorionic Villus Sampling. Medical Research Council European trial of chorionic villus sampling. Lancet 1991;337:1491-9.

3 Brambati B, Lanzani A, Tului $L$. Transabdominal versus transcervical chorionic villus sampling: efficiency and risk evaluation of 2,411 cases. Am f Med Genet 1990;35:160-4.

4 Firth HV, Boyd PA, Chamberlain P, Mackenzie IZ, Lindenbaum RH, Huson SM. Severe limb abnormalities after chorionic villus sampling at 56-66 days' gestation. Lancet 1991;337:762-3. Mastroiacovo P, Cavalcanti DP. Limb-reduction defects and chorionic villus sampling. Lancet 1991;337:1091.

6 Hsieh F, Chen D, Tseng L, Lee C, Ko T, Chuang S, et al. Limb-reduction defects and chorionic villus sampling. Lancet 1991;337:1091-2.

Miny P, Holzgreve W, Horst J, Lenz W. Limb abnormalities and chorionic villus sampling. Lancet 1991;337:1423-4.

8 Mahoney MJ, for the USNICHD Collaborative CVS Study Group. Limb abnormalities and chorionic villus sampling. Lancet 1991;333:1422-3.

9 Jackson LG, Wapner RJ, Brambati B. Limb abnormalities and chorionic villus sampling. Lancet 1991;337:1423.

10 Froster-Iskenius UG, Baird PA. Limb reduction defects in over one million consecutive livebirths. Teratology 1989;39:127-35

11 Lilford RJ. Invasive diagnostic procedures. In: Prenatal diagnosis and prognosis. London: Butterworths, 1990:208-25.

12 Gosden CM. Fetal karyotyping using chorionic villus samples. In: Drife JO, Donnai D, eds. Antenatal diagnosis of fetal abnormalities. Berlin: Springer Verlag, 1991:153-67.

13 Lilford R. Trade-off between gestational age and miscarriage risk of prenatal testing: does it vary according to genetic risk? Lancet 1990;336:1303-5.

14 Lilford RJ, Irving H, Gupta JK, O'Donovan P, Linton G. Transabdominal chorionic villus biopsy versus amniocentesis for diagnosis of aneuploidy: safety is not enough. In: Chapman $M$, Grudzinskas G, Chard T, Maxwell D, eds. The embryo-normal and abnormal development and growth. Berlin: Springer Verlag, 1990:91-100.

15 Tabor A, Madsen M, Obel EB, Philip J, Bang J, Noorgaard-Pederson B. Randomised controlled trial of genetic amniocentesis in 4,606 low-risk women. Lancet 1986;i:1287-93.

16 Heslop AF, Fairweather DVI, Blackwill RJ, Howard S. The effect of amniocentesis and drainage of amniotic fluid on lung development in maca fascicularis during fetal and postnatal life. $\mathrm{Br} \mathcal{F}$ Obstet Gynaecol 1984;91:835-42.

17 Orrell RW, Lilford RJ. Chorionic villus sampling and rare side effects. Will a randomised trial detect them? Int 7 Gynecol Obstet 1990;32:29-34.

18 Guiding the knife. The Economist 1991 May 4-10:11.

\section{The right to know}

\section{Patients' records should be understandable by patients, too}

Patients have had access to their computerised medical records since 1984 and from next month will have access to their written records as well. ${ }^{1}$ Is it time to go even further down this path?

Many doctors find the prospect of patients reading their records disquieting. Recent reviews, however, have emphasised the benefits of giving patients greater access, ${ }^{23}$ echoing the advice of 20 years ago. Analysing the consequences of American legislation to give patients access to their entire medical record, Shenkin and Warner concluded that open access would improve patients' adherence to treatment, improve the efficiency of the service, and strengthen the role of the profession. ${ }^{4}$

Concern that sharing information with patients may cause sustained psychological distress is probably unfounded. Showing them incomprehensible jargon or pejorative comments will understandably confuse or distress, but this is a powerful argument for changing the way records are written, not keeping them secret. Danish patients have a statutory right to see their entire hospital record; in one large teaching hospital only $0.4 \%$ of patients exercised this right during one year. Both doctors and patients regarded access positively, and no ill effects were observed. ${ }^{5}$

Psychiatric patients may respond less favourably than other patients shown their records. Although a study in general practice $^{6}$ and another of psychiatric outpatients reported in this week's journal ( $\mathrm{p} 967)^{7}$ suggest that this might be true, another of forensic patients given access to the daily record made by all disciplines thought that they were "better able to discuss their problems with staff, better able to put forward their own views and considered that access enabled them to correct errors." "It has been argued that the short term distress suffered by some psychiatric patients may in the longer term be therapeutic. ${ }^{9}$

Other arguments used against giving patients greater access to their records are that modifying records to make them comprehensible and palatable to patients would require too much effort ${ }^{10}$ and that doctors might restrict their notes to the 